\title{
Oral Residue Following Swallowing
}

National Cancer Institute

\section{Source}

National Cancer Institute. Oral Residue Following Swallowing. NCI Thesaurus. Code C127208.

An observation of oral residue remaining after an individual swallows. 